\title{
TRANSIENT UNILATERAL BLINDNESS FOLLOWING GENERAL ANAESTHESIA: CASE REPORT
}

\author{
K.A. Munn, R.T. Williams, and C.M. Shafto
}

A WIDE VARIETY of visual disturbances following general anaesthesia and surgery have been reported from time to time. ${ }^{1,2}$ These disturbances have resulted from direct trauma to the eye, ${ }^{3-5}$ or as a complication of the anaesthetic or surgical procedure. ${ }^{2}$

While direct pressure on the eye from a variety of headrests is well known $n^{4}$ and pressure exerted by a mask has been clearly implicated in causing visual disturbances, ${ }^{5}$ very few, if any, reports are to be found in the recent literature.

\section{Report of a CASE}

On January 20, 1976, Miss J.P. underwent an arthrotomy of the right knee with a medial menisectomy and repair of the medial collateral ligament. Miss J.P, was a healthy 22-year-old on oral contraceptives whose only relevant previous history was infectious hepatitis as a child. Induction was achieved with sodium thiopentone and anaesthesia was maintained with nitrous oxide and oxygen 3:3 litres/minute and enflurane, using a size 3 British Oxygen Company (BOC) malleable face mask with inflatable pad, which was held in position with a neoprene head strap. No difficulty was encountered with the airway. The operation was conducted under tourniquet control and blood loss was minimal. The patient's cardiovascular status was normal throughout the operation with no periods of hypotension or hypertension. No significant changes in blood pressure accurred with the release of the tourniquet. Duration of the anaesthetic was one hour and 55 minutes, which was much longer than had been expected. On transfer to the recovery room it was noted that there was erythema on the face from the pressure of the mask partly covering the left eyelids, but this did not appear excessive. At 1125 hrs, 20 minutes after discontinuing the anaesthetic, the patient complained of being un-

K.A. Munn, C.D., M.D., Resident Anaesthetist, R.T. Williams, M.D., F.R.C.P.(C), Staff Anaesthetist, D.M. Strafto, D.O.M.S., F.R.C.S.(C), Chief, Department of Ophthalmology, Foothills Hospital, 1403-29th Street N.W., Calgary, Alta., T2N 2T9. able to see with her left eye. An ophthalmic consultation was immediately obtained which confirmed the absence of light perception and an afferent pupil. There was injection of the conjunctiva medially and a slight reddening of the left upper eyelid. There was no evidence of corneal injury. The fundus was normal and there was no retinal oedema. The circulation of all retinal vessels appeared normal. Immediate treatment was initiated with 10 per cent Rheomacrodex and increasing $\mathrm{PCO}_{2}$ by rebreathing. At $1225 \mathrm{hrs}$, the patient was able to see moving fingers and at 1400 hrs was able to see shapes and colours. By 1630 hrs she was able to read a magazine. On February 3 she reported that her vision was, "good and not blurred in any way". Her final ophthalmic status revealed a scotoma as shown on the visual field with a pigmentary disturbance in the corresponding area of retina. Her visual actuity is $6 / 6+$.

\section{Discussion}

The primary purpose in reporting this case is to draw current attention to a problem which has received little, if any, recent consideration.

It is probable that the transient blindness was due to partial or complete occlusion of the central retinal artery caused by excessive pressure on the globe by the mask. The evidence of medial conjunctival injection and erythema of the medial aspect of the left upper eyelid under the site of the mask confirms this.

A method of measuring pressure exerted by a mask on the face or on the globe was developed. Using British Oxygen Company (BOC) malleable face masks with inflatable pads, sized from 0-6. it was found that the pressure exerted through a sphygmomanometer connected to the air plug could be correlated with the pressure exerted on the face as shown in Table 1 . From this it was ascertained that the average pressure applied to the face by consultant and resident anaesthetists in our hospital was $3.99 \mathrm{kPa}(30 \mathrm{~mm} \mathrm{Hg})$ when the mask was hand-held and $5.99 \mathrm{kPa}(45 \mathrm{~mm} \mathrm{Hg})$ when the mask was held in place with a head 
TABLE I

Pressure kPa (mm Hg) Exerted on the Face by a boC Malleable face Mask With Inflatable Pad

\begin{tabular}{llllll}
\hline $\begin{array}{c}\text { Pressure in the } \\
\text { Mask } \\
\text { size }\end{array}$ & & & & & \\
\hline 0 & $1.33(10)$ & $2.66(20)$ & $3.99(30)$ & $5.32(40)$ & $6.65(50)$ \\
1 & $2.93(22)$ & $4.26(32)$ & $5.32(40)$ & $5.32(40)$ & $5.99(45)$ \\
2 & $3.33(25)$ & $3.99(30)$ & $4.66(35)$ & $5.32(40)$ & $5.99(45)$ \\
3 & $3.33(25)$ & $3.99(30)$ & $4.79(36)$ & $5.59(42)$ & $6.65(50)$ \\
4 & $2.66(20)$ & $3.99(30)$ & $4.66(35)$ & $5.32(40)$ & $5.85(44)$ \\
5 & $3.19(24)$ & $3.46(26)$ & $3.99(30)$ & $5.05(38)$ & $5.85(44)$ \\
6 & $3.19(24)$ & $3.99(30)$ & $5.05(38)$ & $5.85(44)$ & $6.65(50)$ \\
\hline
\end{tabular}

strap. It is unlikely that this pressure is sufficient to cause occlusion of the central retinal artery.

Two types of head straps are available in our hospital. Type $I$ is manufactured of very flexible black rubber, while Type 2 is of black neoprene. Type 2 is currently being purchased because it is not as subject to rubber rot associated with contact with anaesthetic agents and repeated sterilization. It has been found that use of the neoprene strap is more likely to result in higher pressures being exerted on the face because of its poorer flexibility and elasticity.

In the case reported the mask was held in place with a neoprene strap. Although the anaesthetic circuit came over the right side of the head, the injury was to the left eye. This suggests that the tension on the left side of the strap was greater and introduces the possibility that strap pressure may have been exerted over the left carotid artery.

It is possible that diminution of arterial pressure due to pressure over the left carotid artery together with excessive pressure exerted on the globe by the mask may have been sufficient to produce marked ischaemia of the retina. The prompt return of vision suggest s ischaemia rather than infarct.

It is recognized that an oculo-cardiac reflex can be effected by excessive mask pressure. There is no evidence to suggest this in the present case and no significant arrhythmias were noted.

The anaesthetists who were involved in this incident are of the opinion that the primary cause was poor anaesthetic technique. The lack of recent reports concerning post-anaesthetic blindness may have led to a decrease in the emphasis placed on this aspect of mask technique. It appears that such a decrease in emphasis is not warranted. However, since post-anaesthetic blindness is indeed rare now (or at least unreported), the consultant ophthalmologist feels that it is likely that some other circulatory abnormality was present in this case in addition to pressure from the mask. Although it is known that the patient was taking oral contraceptives, it has not been possible to confirm or deny the possibility of coagulation abnormalities.

\section{SUMMARY}

A case is reported of transient unilateral blindness following general anaesthesia with a face mask. The most likely explanation for this is central retinal artery occlusion, either partial or complete, due to excessive pressure from the mask exerted on the globe. This pressure may be increased with the use of neoprene head straps as opposed to the more flexible and elastic rubber straps. Pressure from the strap over the carotid artery may be a factor in reducing the central retinal arterial pressure, thus making it more susceptible to occlusion by mask pressure.

\section{RÉSUMÉ}

Les auteurs rapportent un épisode de cécité transitoire affectant l'un des yeux à la suite d'une anesthésie générale au masque. L'explication la plus plausible de cette complication est une occlusion partielle ou totale de l'artère centrale de la rétine, secondaire à une compression excessive du globe oculaire par le masque. Les courroies de néoprène sont plus susceptibles de permettre la fixation du masque avec une pression excessive que celles de caoutchouc. De plus, une courroie peut comprimer une artère carotide au niveau du 
cou avec diminution de la pression dans l'artère rétinienne.

\section{REFERENCES}

1. Goldsmith, M.O. Occlusion of the central retinal artery following retrobulbar hemorrhage. Ophthalmologica 153(3): 191 (1967).

2. Arbus, L..., Fabre, J., Bechac, G., \& Lazorthes, Y. Clinical, ophthalmoscopic and biologic findings in systemic fat embolism. Acta Neurochir. (Wien) $29(l): 89(1973)$,
3. Snow, J.C., Kripke, F.J., Norton, M.L. Chandra, P., \& Woodcome, H.A. Corneal injuries during general anaesthesia. Anesth. Analg. $54(4): 465$ (1975).

4. Hollenhorst, R.W., SVien, H.J., \& Benoit, C Unilateral blindness occul'ring during anaesthesia for neurosurgical operations. Arch. Ophth. 52: 819 (1954).

5. GIVNER, I. \& JAFFE, N.S. Occlusion of the central retinal artery following anaesthesia. Arch. Ophth. 43: 197 (1950). 